\title{
Associations between eating habits and glycemic control and obesity in Japanese workers with type 2 diabetes mellitus
}

This article was published in the following Dove Press journal: Diabetes, Metabolic Syndrome and Obesity:Targets and Therapy

\author{
Maki Gouda' \\ Miyuki Matsukawa ${ }^{2}$ \\ Hiroaki lijima ${ }^{3}$ \\ 'Medical Intelligence Department, \\ Ikuyaku. Integrated Value \\ Development Division, Mitsubishi \\ Tanabe Pharma Corporation, Tokyo, \\ Japan; ${ }^{2}$ Data Science Department, \\ Ikuyaku. Integrated Value \\ Development Division, Mitsubishi \\ Tanabe Pharma Corporation, \\ Osaka, Japan; ${ }^{3}$ Medical Affairs \\ Department, Ikuyaku. Integrated Value \\ Development Division, Mitsubishi \\ Tanabe Pharma Corporation, Tokyo, \\ Japan
}

Purpose: To investigate the impact of poor eating habits on glycemic and metabolic control, we analyzed the associations between eating behaviors and $\mathrm{HbAl} \mathrm{c}$ and body mass index (BMI) in Japanese workers with type 2 diabetes mellitus (T2DM).

Subjects and methods: The Japan Medical Data Center database of workers' medical health insurance claims was used to identify individuals with T2DM who were receiving antidiabetic medication between April 2012 and March 2015 (the primary analysis population). The database included routine medical check-up results and responses to questions on lifestyle and eating habits. Using these, we retrospectively analyzed the associations between the individuals' eating habits and their HbA1c levels and BMIs.

Results: In total, 31,722 individuals were included in the primary analysis. The mean values of $\mathrm{HbA1c}$ and BMI were $7.27 \%$ and $26.29 \mathrm{~kg} / \mathrm{m}^{2}$, respectively; these tended to be higher among the younger population. Approximately $36 \%$ of the individuals regularly ate supper within 2 hours of bedtime, $14.5 \%$ regularly consumed late-night snacks, and $13.4 \%$ regularly skipped breakfast. Each of these eating habits correlated significantly with higher $\mathrm{HbA} 1 \mathrm{c}$ and BMI. In addition, the population with two or all three of these poor dietary habits showed the highest association with $\mathrm{HbA} 1 \mathrm{c} \geq 7.0 \%$ and $\mathrm{BMI} \geq 25 \mathrm{~kg} / \mathrm{m}^{2}$. Approximately $38 \%$ of workers ate fast. Fast eating was significantly associated with BMI $\geq 25 \mathrm{~kg} / \mathrm{m}^{2}$ but not with $\mathrm{HbA} 1 \mathrm{c} \geq 7.0 \%$.

Conclusion: Poor eating habits were significantly associated with poor glycemic and body weight control in Japanese workers with T2DM. Improved eating habits may help with glycemic and body weight management.

Keywords: type 2 diabetes, workers, eating habits, glycemic control, obesity

\section{Introduction}

People with type 2 diabetes mellitus (T2DM) are at high risk of developing diabetic complications and life-threatening complications such as cardiovascular diseases, ${ }^{1}$ which can reduce their quality of life and labor productivity. ${ }^{2,3}$ The Japan Epidemiology Collaboration on Occupational Health (J-ECOH) study, an epidemiological study of the workforces of several companies in Japan, reported that $8.0 \%$ of men and $3.3 \%$ of women had diabetes, whereas $14.1 \%$ of men and $9.2 \%$ of women had prediabetes, and that the prevalence of both T2DM and prediabetes increased with age, especially among middle-aged workers. ${ }^{4}$ Although T2DM is largely a self-managed disease, it may be difficult for Japanese workers to maintain daily metabolic control because many place a higher priority on their work than on their health. ${ }^{5}$ In addition, the
Correspondence: Maki Gouda Ikuyaku. Integrated Value Development Division, Mitsubishi Tanabe Pharma Corporation, 17-10, NihonbashiKoamicho, Chuo-ku, Tokyo 103-8405, Japan

Tel +8I 367487707

$\mathrm{Fax}+81336636773$

Email gouda.maki@mm.mt-pharma.co.jp 
dietary self-management of Japanese workers with T2DM is often affected by work-related factors, such as night shifts, workplace conformity, working overtime, and participation in workplace events. ${ }^{6}$

Eating habits show strong relationships with age and cultural, social, economic, and psychological determinants and are integrated into the individual's daily routine over a long period. Meal frequency and times of eating can have a significant effect on various cardiac and metabolic parameters. ${ }^{7}$ Several epidemiological studies of healthy adults and patients with T2DM have shown that poor eating habits, such as eating supper or snacking late at night and skipping breakfast, are associated with hyperglycemia and obesity, ${ }^{8-11}$ as well as predisposing individuals to developing T2DM. ${ }^{12,13}$ The timing of meals plays a critical role in regulating human internal circadian rhythms. ${ }^{14}$ However, there have been only few investigations of the association between metabolic parameters and eating habits in workers with T2DM.

This retrospective, cross-sectional study using a medical claim database analyzed the relationship between eating habits and metabolic parameters in Japanese workers with T2DM in real world.

\section{Subjects and methods Database}

Under the Industrial Safety and Health Act, workers in Japan are legally obliged to undergo a health examination at least annually, and medical records are held in databases of the health insurance societies. ${ }^{15}$ We obtained the available prescription and health examination records for the period from April 2009 to March 2015 held in the medical database of the Japan Medical Data Center (JMDC). This database stores a wealth of data on Japanese workers, uploaded from the databases of the health insurance societies. It holds not only medical claims but also records from medical check-ups, including clinical laboratory measurements and self-reports of lifestyle. It is possible to track individual workers over multiple periods of medical treatment. This study was not reviewed by an ethical committee and informed consent was not required, as this was a retrospective, observational study using a commercial database with anonymized data.

\section{Study subjects}

In this study, workers were defined as insured members of health insurance associations, but not their nonworking dependents. To exclude the workers with suspected T2DM, patients with a diagnosis of diabetes and a documented prescription for antihyperglycemic agents at least once during the period April-March of each year of the study period were included in this study. T2DM was identified by a disease classification code of either E11 (non-insulin-dependent diabetes mellitus) or E14 (unspecified diabetes mellitus) in the ICD (2003 version). Antihyperglycemic agents include those with the following Anatomical Therapeutic Chemical classification system subcodes: A10C, human insulins/insulin analogs; A10H, sulfonylureas; A10J, biguanides; A10K, thiazolidinediones; A10L, $\alpha$-glucosidase inhibitors; A10M, glinides; A10N, dipeptidyl peptidase-4 (DPP-4) inhibitors; A10P, sodium-glucose co-transporter-2 inhibitors; and A10S, glucagon-like peptide-1 receptor agonists. The database included responses to questions asked in health check-ups, including about eating, exercise, and smoking habits, alcohol consumption, and sleep status.

The primary analysis set comprised workers who had measurements of HbA1c and body mass index (BMI) in a medical check-up conducted between April 2012 and March 2015 and who had provided answers to the following four questions on eating habits:

- Do you eat supper (ie, the evening meal) within 2 hours of bedtime at least three times per week? (Yes/No)

- Do you skip breakfast at least three times per week? (Yes/ No)

- Do you eat snacks after supper at least three times per week? (Yes/No)

- How does your eating speed compare with that of other people? (Fast/Normal/Slow)

Data from April 2009 to March 2012 were excluded from the primary analysis set to avoid possible effects on $\mathrm{HbAlc}$ and BMI of the rapid increase in prescriptions of DPP-4 inhibitors (Figure S1A). The mean HbA1c and BMI levels for the population were constant between April 2012 and March 2015 (Figure S1B and C).

When two or more medical check-up records were available for one worker, the most recent data were used.

\section{Outcome and data analysis}

The primary end point was the associations of eating habits with HbA1c and BMI. For the primary analysis set, least squares (LS) means and standard errors were calculated for HbA1c and BMI, and covariance analysis was performed in which sex, age, exercise habits, sleep, alcohol consumption, and diabetes treatment history (prescription record of antihyperglycemic agents within 3 months before medi- 
cal check-up) were considered as covariates in subgroups according to eating habits. For each eating habit, LS means and 95\% CIs were calculated to analyze differences between groups (Yes vs No).

The proportions of workers with $\mathrm{HbA} 1 \mathrm{c} \geq 7.0 \%$ and $<7.0 \%$, and with BMI $\geq 25 \mathrm{~kg} / \mathrm{m}^{2}$ and $<25 \mathrm{~kg} / \mathrm{m}^{2}$, were calculated. A HbA1c level of $7.0 \%$ is the glycemic goal recommended by the Japanese Diabetes Society to avoid complications, ${ }^{16}$ and BMI $\geq 25 \mathrm{~kg} / \mathrm{m}^{2}$ is the cut-off point for obesity defined by the Japan Society for the Study of Obesity. ${ }^{17}$ Subgroups were defined based on the responses to the eating habit questions (Yes vs No; Fast vs [Normal + Slow]; Fast vs Normal). Differences between these subgroups in the ratios of workers with $\mathrm{HbA} 1 \mathrm{c} \geq 7.0 \%$ vs $<7.0 \%$ and $\mathrm{BMI} \geq 25$ $\mathrm{kg} / \mathrm{m}^{2}$ vs $<25 \mathrm{~kg} / \mathrm{m}^{2}$ were evaluated using Fisher's exact test. In addition, ORs and 95\% CIs were calculated using a multivariate logistic regression model to analyze the differences between the eating habit subgroups with sex, age, exercise habits, sleep, alcohol consumption, and diabetes treatment history as covariates.

In this study, eating supper within 2 hours before bedtime, skipping breakfast, and eating snacks after supper were considered to be poor eating habits. We investigated the effects of single or multiple poor eating habits on $\mathrm{HbA} 1 \mathrm{c}$ and BMI in an ad hoc analysis. Workers were considered to be without poor eating habits if they answered "No" to all three eating habit questions; this subgroup served as a reference. The remaining workers were grouped according to whether they answered "Yes" to one or to two or more of the three questions (referred to as "single" and "multiple" poor eating habits, respectively). The proportions of workers in these subgroups with $\mathrm{HbA} 1 \mathrm{c} \geq 7.0 \%$ and $<7.0 \%$, and with $\mathrm{BMI} \geq 25 \mathrm{~kg} / \mathrm{m}^{2}$ and $<25 \mathrm{~kg} / \mathrm{m}^{2}$, were compared with those in the control population using Fisher's exact tests. Multivariate logistic regression models were used to examine the effect of multiple poor eating habits on glycemic control and obesity in the same way as was described above.

The statistical analyses were performed by JMDC using SAS ver.9.3 (SAS Institute Inc., Cary, NC, USA).

\section{Results Characteristics of the primary analysis set}

In total, 3,621,610 records were provided by JMDC, of which 1,836,555 were for insured members; 66,890 of these were identified as records of workers with T2DM receiving treatment with antihyperglycemic agents (Figure S2). Of these, 33,397 records met the inclusion criteria as those of workers with T2DM and medical records, and 31,722 workers with medical check-up records between April 2012 and March 2015 were included in the primary analysis set. Their characteristics are shown in Table 1 . More than $90 \%$ of the workers were male, and the mean age was 54.7 years. The mean $\mathrm{HbA} 1 \mathrm{c}$ and BMI were $7.27 \%$ and $26.29 \mathrm{~kg} / \mathrm{m}^{2}$, respectively. There was no significant correlation between $\mathrm{HbA} 1 \mathrm{c}$ levels and BMI (data not shown). Interestingly, HbAlc and BMI tended to be higher in the young age groups; the mean $\mathrm{HbA1c}$ and BMI values were the highest for the age group 20-40 years (Figure 1).

More than one-third of the workers regularly ate supper within 2 hours of bedtime, and $14.5 \%$ regularly ate snacks after supper (Table 1$)$. The majority of workers $(86.6 \%)$ ate breakfast five or more times a week, but $13.4 \%$ did not. Approximately $38 \%$ of workers ate fast compared with other people. Approximately $75 \%$ of the workers did not exercise regularly, $36.5 \%$ were smokers, and almost $60 \%$ consumed alcohol daily/sometimes.

\section{Effect of eating habits on glycemic control and obesity}

Workers who ate supper within 2 hours of bedtime, skipped breakfast, and ate snacks after supper had significantly higher HbAlc than those who did not $(P<0.001$; Table 2$)$. The proportion of workers with $\mathrm{HbA} 1 \mathrm{c} \geq 7.0 \%$ was greater in the subgroups with these eating habits $(P<0.001$; Table 3). Multivariate logistic regression analysis confirmed that skipping breakfast was significantly associated with $\mathrm{HbA} 1 \mathrm{c}$ $\geq 7.0 \%$ (OR 1.33, 95\% CI 1.24-1.42; $P<0.001$ ) (Figure 2A). Eating supper within 2 hours of bedtime or eating snacks after supper was also significantly associated with $\mathrm{HbAlc}$ $\geq 7.0 \%$ (OR 1.18, 95\% CI 1.12-1.25, and OR 1.18, 95\% CI 1.10-1.26, respectively; both $P<0.001$ ). However, a fast eating speed was not associated with a change in $\mathrm{HbAlc}$ (Figure 2A).

The workers with the habit of eating supper within 2 hours of bedtime, skipping breakfast, eating snacks after supper, and eating faster had significantly higher BMIs $(P<0.001)$ (Table 2). A significantly greater proportion of workers with these eating habits had BMI $\geq 25 \mathrm{~kg} / \mathrm{m}^{2}(P<0.001)$ (Table 3 ). Multivariate logistic regression analysis showed that eating supper within 2 hours of bedtime, skipping breakfast, and eating snacks after supper were significantly associated with BMI $\geq 25 \mathrm{~kg} / \mathrm{m}^{2}$ (OR 1.24, 95\% CI 1.18-1.31; OR 1.27, 95\% CI 1.18-1.37; and OR 1.39, 95\% CI 1.29-1.49, respectively; all $P<0.001$ ). Eating fast was also significantly associated with BMI $\geq 25 \mathrm{~kg} / \mathrm{m}^{2}$ (OR 1.53, 95\% CI 1.46-1.61 [vs Nor- 
Table I Characteristics of workers with T2DM (primary analysis set)

\begin{tabular}{|c|c|c|c|c|c|}
\hline \multicolumn{2}{|c|}{ No. of workers with T2DM } & \multicolumn{4}{|l|}{31,722} \\
\hline Sex, male & $\mathrm{n}(\%)$ & 29,147 (91.9) & & & \\
\hline Age (years) & Mean \pm SD & $54.7 \pm 8.2$ & & & \\
\hline $\mathrm{HbAlc}(\%)$ & Mean \pm SD & $7.27 \pm 1.34$ & & & \\
\hline \multirow[t]{5}{*}{ Categories } & $<6.0, \mathrm{n}(\%)$ & $2,778(8.8)$ & & & \\
\hline & $6.0-6.9, \mathrm{n}(\%)$ & I3,045 (4I.I) & & & \\
\hline & 7.0-7.9, n (\%) & $9,157(28.9)$ & & & \\
\hline & 8.0-8.9, n (\%) & $3,552($ (II.2) & & & \\
\hline & $\geq 9.0, \mathrm{n}(\%)$ & $3,190(10.1)$ & & & \\
\hline BMI $\left(\mathrm{kg} / \mathrm{m}^{2}\right)$ & Mean \pm SD & $26.29 \pm 4.58$ & & & \\
\hline \multirow[t]{5}{*}{ Categories } & $<18.5, \mathrm{n}(\%)$ & $444(1.4)$ & & & \\
\hline & $|8.5-2| .9, \mathrm{n}(\%)$ & $4,248(13.4)$ & & & \\
\hline & $22.0-24.9, \mathrm{n}(\%)$ & $8,963(28.3)$ & & & \\
\hline & $25.0-29.9, \mathrm{n}(\%)$ & $12,278(38.7)$ & & & \\
\hline & $\geq 30.0, \mathrm{n}(\%)$ & $5,789(18.2)$ & & & \\
\hline \multirow[t]{9}{*}{ Eating habits } & Eating supper within & Yes & No & & \\
\hline & 2 hours of bedtime & & & & \\
\hline & $\mathrm{n}(\%)$ & II,464 (36.I) & $20,258(63.9)$ & & \\
\hline & Skipping breakfast & Yes & No & & \\
\hline & $\mathrm{n}(\%)$ & $4,249(13.4)$ & $27,473(86.6)$ & & \\
\hline & Eating snacks after supper & Yes & No & & \\
\hline & $\mathrm{n}(\%)$ & $4,594(14.5)$ & $27,128(85.5)$ & & \\
\hline & Eating speed & Fast & Normal & Slow & \\
\hline & n (\%) & II,947 (37.7) & $17,250(54.4)$ & $2,525(8.0)$ & \\
\hline \multirow[t]{2}{*}{ Exercise habit ${ }^{\mathrm{a}}$} & & No & Yes & Unidentified/unlisted & \\
\hline & $\mathrm{n}(\%)$ & $23,767(74.9)$ & $7,928(25.0)$ & $27(0.1)$ & \\
\hline \multirow[t]{2}{*}{ Smoking habit } & & No & Yes & Unidentified/unlisted & \\
\hline & $\mathrm{n}(\%)$ & $20,131(63.5)$ & II,577 (36.5) & $14(0.0)$ & \\
\hline \multirow[t]{2}{*}{ Alcohol consumption } & & Daily & Sometimes & Rarely & Unidentified/unlisted \\
\hline & n (\%) & $8,876(28.0)$ & 9,908 (31.2) & $12,723(40.1)$ & $215(0.7)$ \\
\hline \multirow[t]{2}{*}{ Adequate sleep } & & No & Yes & Unidentified/unlisted & \\
\hline & n (\%) & 12,669 (39.9) & $18,553(58.5)$ & $500(1.6)$ & \\
\hline
\end{tabular}

Note: ${ }^{a}$ Exercising regularly to a light sweat for $>30$ minutes at a time, twice weekly, for $>\mid$ year.

Abbreviations: BMI, body mass index; T2DM type 2 diabetes mellitus; HbAlc, glycated hemoglobin.

mal + Slow]; OR 1.49, 95\% CI 1.42-1.57 [vs Normal]; both $P<0.001$ ) (Figure 2B).

\section{Effects of single and multiple poor eating habits}

Because the three poor eating habits were associated with worse levels of $\mathrm{HbA} 1 \mathrm{c}$ and BMI, we examined the association of glycemic and body weight control with single and multiple poor eating habits in an ad hoc analysis. The numbers of workers with single and multiple poor eating habits were 11,093 and 4,304, respectively (Table 4); these workers tended to be younger, to be smokers, to exercise less, and to have inadequate sleep. The prevalence of $\mathrm{HbA} 1 \mathrm{c} \geq 7.0 \%$ and $\mathrm{BMI} \geq 25.0 \mathrm{~kg} / \mathrm{m}^{2}$ was significantly greater among the workers with single and multiple poor eating habits than among those without (Table 4). Multivariate logistic regression analysis demonstrated that single and multiple poor eating habits were significantly associated with $\mathrm{HbA} 1 \mathrm{c} \geq 7.0 \%$ (OR $1.16,95 \%$ CI $1.10-1.22$, and OR $1.43,95 \%$ CI $1.33-1.54$, respectively; both $P<0.001$ ) (Figure $3 \mathrm{~A}$ ) and $\mathrm{BMI} \geq 25.0$ $\mathrm{kg} / \mathrm{m}^{2}$ (OR 1.33, 95\% CI 1.26-1.40, and OR 1.49, 95\% CI 1.37-1.61, respectively; both $P<0.001$ ) (Figure 3B). The ORs for both $\mathrm{HbA} 1 \mathrm{c} \geq 7.0 \%$ and $\mathrm{BMI} \geq 25.0 \mathrm{~kg} / \mathrm{m}^{2}$ were higher for the workers with multiple poor eating habits than for those with a single poor eating habit.

\section{Discussion}

This study analyzed data from the JMDC database for medical insurance associations, which is one of the largest medical databases with medical check-up data in Japan. Because the selected data sets were for insured members with a diagnosis of T2DM and prescribed antihyperglycemic medication, the subjects of this study were considered to be workers with T2DM. The results of the study showed clear associations 


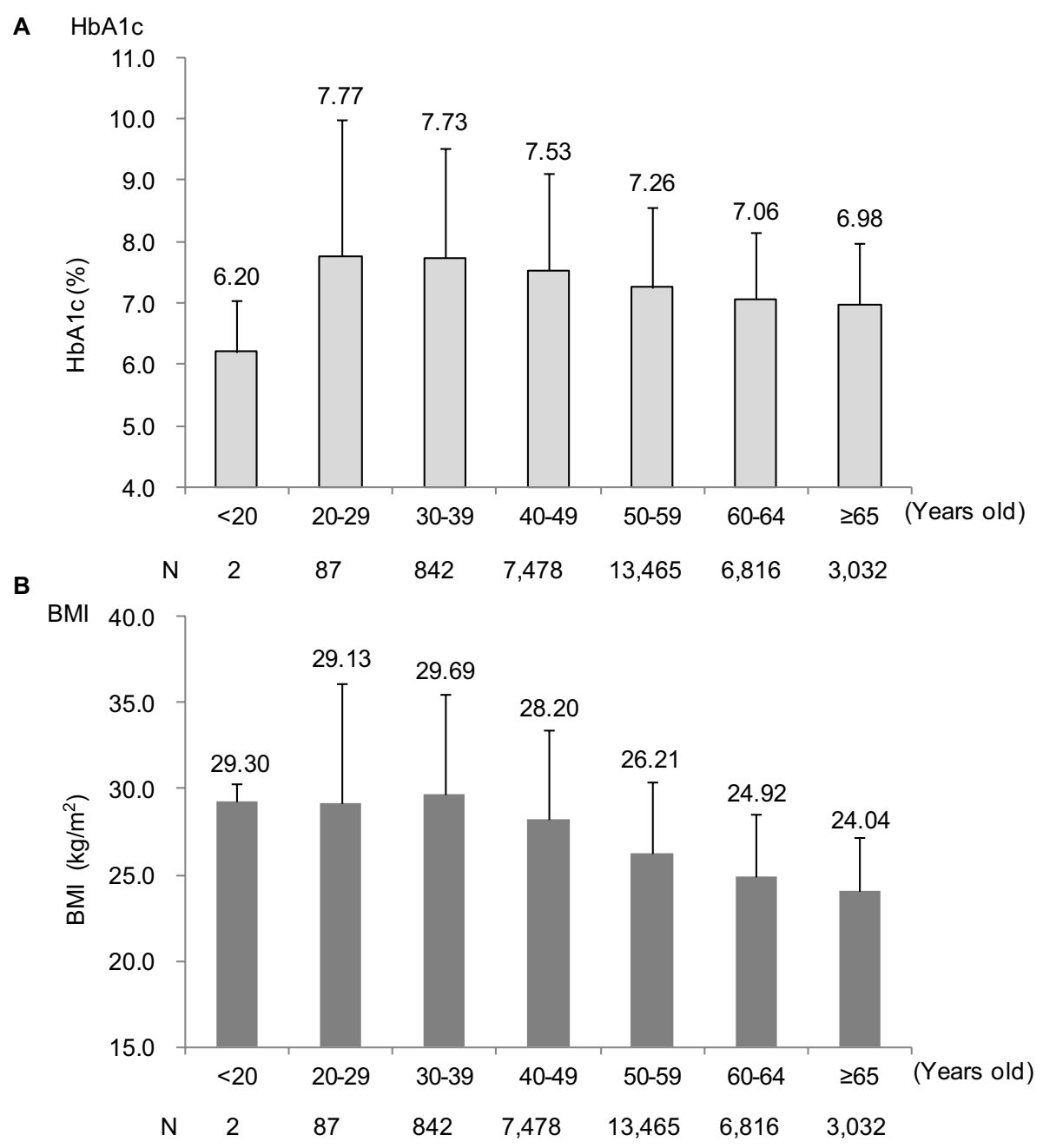

Figure I Mean (A) HbAlc and (B) BMI by age (primary analysis set). Note: Error bars show SDs of the mean.

Abbreviations: BMI, body mass index; HbAlc, glycated hemoglobin.

between some eating habits and poor glycemic control and obesity, even under treatment with antidiabetic medication.

In the primary analysis set, mean $\mathrm{HbA} 1 \mathrm{c}$ and BMI values were similar to those previously reported for workers with T2DM. ${ }^{4}$ Approximately half of the workers had not achieved the therapeutic goal of $\mathrm{HbA} 1 \mathrm{c}<7.0 \%$, more than half were obese with BMI $\geq 25.0 \mathrm{~kg} / \mathrm{m}^{2}$, and approximately one-fifth were severely obese with BMI $\geq 30 \mathrm{~kg} / \mathrm{m}^{2}$. Taken together, obesity and poor glycemic control remain issues for workers with T2DM, despite taking antihyperglycemic medication.

The HbAlc and BMI levels tended to be higher in the younger workers. In the general population, young people often show less healthy eating habits compared with older generations. ${ }^{18-20}$ Of the 929 workers aged $20-40$ years in the primary analysis set, $428(46.1 \%)$ regularly ate supper within 2 hours of bedtime, 225 (24.2\%) skipped breakfast more than three times a week, and 159 (17.1\%) regularly ate snacks after supper; these percentages were higher than for the workers aged $\geq 40$ years (data not shown). Consistent with our data, poor glycemic control and obesity were more frequently reported in younger patients with T2DM. ${ }^{21-23}$ Because early stage of T2DM is often asymptomatic, younger patients being busy with their job may be less motivated to their diabetic condition, have less time to foster a healthy lifestyle, and tend to be less adherent to medication. ${ }^{22,23}$ The National Health and Nutrition Survey in Japan and a study of Japan Clinicians Diabetes Association also reported the higher treatment discontinuation rate for males in the 40's or those diagnosed with T2DM in their 40's. ${ }^{24,25}$ Therefore, a higher rate of poor glycemic control and obesity in young patients is possibly due to poor compliance to proper dietary habits and to treatment. The results suggested that more effective intervention or changes in the lifestyle may be necessary for younger diabetic workers. 
Table 2 The association of eating habits with HbAlc and BMI (primary analysis set)

\begin{tabular}{|c|c|c|c|c|c|c|c|c|}
\hline \multirow[t]{2}{*}{ Question } & \multirow[t]{2}{*}{ Answer } & \multirow[t]{2}{*}{$\mathbf{N}$} & \multicolumn{3}{|c|}{ HbAlc (\%) } & \multicolumn{3}{|c|}{ BMI $\left(\mathrm{kg} / \mathrm{m}^{2}\right)$} \\
\hline & & & $\begin{array}{l}\text { LS mean } \\
\pm S E\end{array}$ & $\begin{array}{l}\text { Difference in LS } \\
\text { mean }[95 \% \mathrm{CI}]\end{array}$ & $P$-value & $\begin{array}{l}\text { LS mean } \\
\pm S E\end{array}$ & $\begin{array}{l}\text { Difference in LS } \\
\text { mean }[95 \% \mathrm{CI}]\end{array}$ & $P$-value \\
\hline Eating supper within & No & 20,258 & $7.65 \pm 0.04$ & & & $27.79 \pm 0.14$ & & \\
\hline 2 hours of bedtime & Yes & 11,464 & $7.76 \pm 0.04$ & $0.10[0.07,0.13]$ & $<0.001$ & $28.21 \pm 0.14$ & $0.42[0.32,0.52]$ & $<0.001$ \\
\hline \multirow[t]{2}{*}{ Skipping breakfast } & No & 27,473 & $7.67 \pm 0.04$ & & & $27.91 \pm 0.14$ & & \\
\hline & Yes & 4,249 & $7.89 \pm 0.05$ & $0.22[0.18,0.26]$ & $<0.001$ & $28.37 \pm 0.15$ & $0.46[0.32,0.60]$ & $<0.001$ \\
\hline Eating snacks after & No & 27,128 & $7.67 \pm 0.04$ & & & $27.85 \pm 0.14$ & & \\
\hline supper & Yes & 4,594 & $7.80 \pm 0.05$ & $0.13[0.09,0.17]$ & $<0.001$ & $28.4 I \pm 0.15$ & $0.56[0.42,0.69]$ & $<0.001$ \\
\hline \multirow[t]{2}{*}{ Fast eating ${ }^{\mathrm{a}}$} & No & 19,775 & $7.70 \pm 0.04$ & & & $27.60 \pm 0.14$ & & \\
\hline & Yes & II,947 & $7.68 \pm 0.04$ & $-0.02[-0.05,0.01]$ & 0.139 & $28.56 \pm 0.14$ & $0.95[0.86,1.05]$ & $<0.001$ \\
\hline \multirow[t]{2}{*}{ Fast eating } & No & 17,250 & $7.68 \pm 0.04$ & & & $27.58 \pm 0.14$ & & \\
\hline & Yes & 11,947 & $7.67 \pm 0.05$ & $-0.02[-0.05,0.01]$ & 0.266 & $28.50 \pm 0.15$ & $0.91[0.81,1.01]$ & $<0.001$ \\
\hline
\end{tabular}

Notes: ${ }^{a} \mathrm{No}=$ Normal + Slow; Yes = Fast; ${ }^{b} \mathrm{No}=$ Normal; Yes = Fast. LS mean was calculated by analysis of covariance (factor: answer [No or Yes]; covariate: sex, age, exercise habits, sleep, alcohol consumption, and diabetes treatment history).

Abbreviations: BMI, body mass index; LS, least squares; SE, standard error; HbAlc, glycated hemoglobin.

Table 3 The association of eating habits with glycemic control and BMI (primary analysis set)

\begin{tabular}{|c|c|c|c|c|c|c|c|}
\hline \multirow[t]{4}{*}{ Question } & \multirow[t]{4}{*}{ Answer } & \multicolumn{3}{|l|}{ HbAlc } & \multicolumn{3}{|l|}{ BMI } \\
\hline & & $\mathrm{n}$ & & & \multirow{2}{*}{\multicolumn{3}{|c|}{$\%[95 \% \mathrm{Cl}]$}} \\
\hline & & \multicolumn{3}{|l|}{$\%[95 \% \mathrm{Cl}]$} & & & \\
\hline & & $<7.0 \%$ & $\geq 7.0 \%$ & $P$-value & $<25 \mathrm{~kg} / \mathrm{m}^{2}$ & $\geq 25 \mathrm{~kg} / \mathrm{m}^{2}$ & $P$-value \\
\hline Eating supper & No & $10,54 \mid$ & 9,717 & & 9,406 & 10,852 & \\
\hline within 2 & & $52.0[51.3,52.7]$ & $48.0[47.3,48.7]$ & & $46.4[45.7,47.1]$ & $53.6[52.9,54.3]$ & \\
\hline hours of & Yes & 5,282 & 6,182 & & 4,249 & 7,215 & \\
\hline bedtime & & $46.1[45.2,47.0]$ & $53.9[53.0,54.8]$ & $<0.001$ & $37.1[36.2,38.0]$ & $62.9[62.0,63.8]$ & $<0.001$ \\
\hline Skipping & No & 13,995 & 13,478 & & 12,246 & 15,227 & \\
\hline \multirow[t]{3}{*}{ breakfast } & & $50.9[50.3,51.5]$ & $49.1[48.5,49.7]$ & & $44.6[44.0,45.2]$ & $55.4[54.8,56.0]$ & \\
\hline & Yes & $\mathrm{I}, 828$ & 2,421 & & $\mathrm{I}, 409$ & 2,840 & \\
\hline & & $43.0[41.5,44.5]$ & $57.0[55.5,58.5]$ & $<0.001$ & $33.2[31.7,34.6]$ & $66.8[65.4,68.3]$ & $<0.001$ \\
\hline Eating snacks & No & 13,732 & 13,396 & & 12,087 & $|5,04|$ & \\
\hline \multirow[t]{3}{*}{ after supper } & & $50.6[50.0,51.2]$ & $49.4[48.8,50.0]$ & & $44.6[44.0,45.1]$ & $55.4[54.9,56.0]$ & \\
\hline & Yes & 2,091 & 2,503 & & 1,568 & 3,026 & \\
\hline & & $45.5[44.1,47.0]$ & $54.5[53.0,55.9]$ & $<0.001$ & $34.1[32.8,35.5]$ & $65.9[64.5,67.2]$ & $<0.001$ \\
\hline \multirow[t]{4}{*}{ Fast eating ${ }^{2}$} & No & 9,875 & 9,900 & & 9,424 & $|0,35|$ & \\
\hline & & $49.9[49.2,50.6]$ & $50.1[49.4,50.8]$ & & $47.7[47.0,48.4]$ & $52.3[51.6,53.0]$ & \\
\hline & Yes & 5,948 & 5,999 & & 4,231 & 7,716 & \\
\hline & & $49.8[48.9,50.7]$ & $50.2[49.3,5 \mathrm{I} .1]$ & 0.799 & $35.4[34.6,36.3]$ & $64.6[63.7,65.4]$ & $<0.001$ \\
\hline \multirow[t]{4}{*}{ Fast eating ${ }^{\mathrm{b}}$} & No & 8,636 & 8,614 & & 8,120 & 9,130 & \\
\hline & & $50.1[49.3,50.8]$ & $49.9[49.2,50.7]$ & & $47.1[46.3,47.8]$ & $52.9[52.2,53.7]$ & \\
\hline & Yes & 5,948 & 5,999 & & 4,231 & 7,716 & \\
\hline & & $49.8[48.9,50.7]$ & $50.2[49.3,5 \mathrm{I} .1]$ & 0.643 & $35.4[34.6,36.3]$ & $64.6[63.7,65.4]$ & $<0.001$ \\
\hline
\end{tabular}

Notes: ${ }^{\mathrm{a}} \mathrm{No}=\mathrm{Normal}+\mathrm{Slow}$; Yes $=$ Fast; ${ }^{\mathrm{N}} \mathrm{No}=\mathrm{Normal}$; Yes $=$ Fast. P-values for the difference in proportion of workers with or without $\mathrm{HbAlc} \geq 7.0 \%$ or $\mathrm{BMI} \geq 25 \mathrm{~kg} / \mathrm{m}^{2}$ were determined by Fisher's exact test.

Abbreviation: BMI, body mass index; HbAlc, glycated hemoglobin.

Although regular exercise improves insulin sensitivity and promotes better glycemic control in patients with T2DM, ${ }^{26}$ it is often difficult for patients to maintain regular exercise habits. In our study, approximately $75 \%$ of workers reported no regular exercise habits, whereas $72.2 \%$ of Japanese male workers without T2DM reported that they did not exercise regularly. ${ }^{27}$ These results suggest that lack of regular, habitual exercise may be a common issue for workers in Japan.

The primary analysis revealed that the three poor eating habits were closely associated with both poor glycemic control and obesity. Previous reports have shown that night eating, including late-night snack, promoted weight gain 


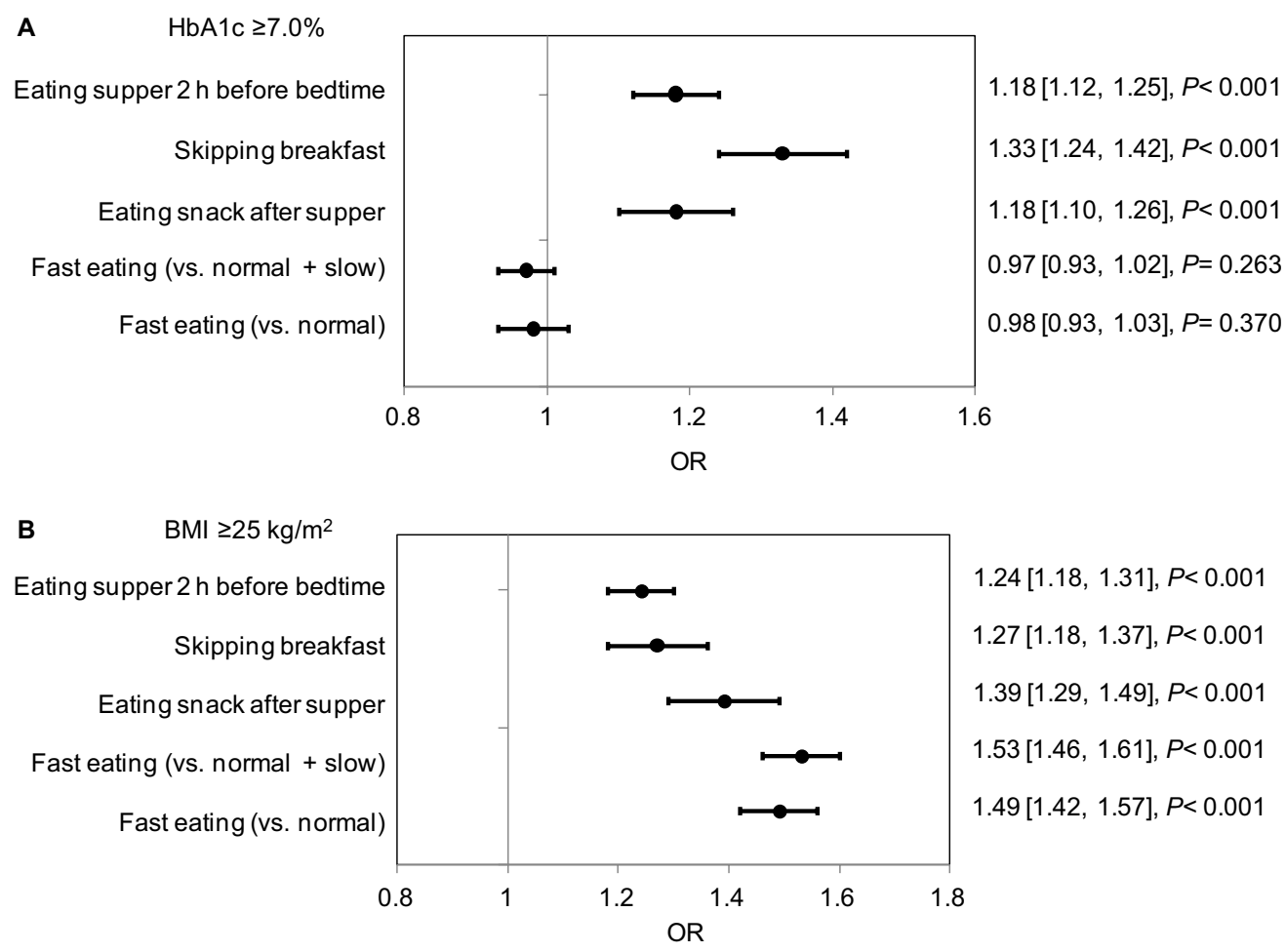

Figure 2 ORs ( $95 \% \mathrm{Cls}$ ) for (A) HbAlc $\geq 7.0 \%$ and (B) BMI $\geq 25 \mathrm{~kg} / \mathrm{m}^{2}$ by eating habit (primary analysis set).

Notes: The ORs, $95 \% \mathrm{Cls}$, and $P$-values were evaluated by multivariate logistic regression using sex, age, exercise habit, sleep, alcohol consumption, and diabetes treatment history as covariates. The reference subgroup was those workers who answered "No" to the questions about eating habits or "Normal" or "Normal" + "Slow" to the question about eating speed.

Abbreviation: BMI, body mass index.

Table 4 The association between single/multiple poor eating habits and $\mathrm{HbAlc}$ and BMI

\begin{tabular}{|c|c|c|c|c|}
\hline & & \multicolumn{3}{|c|}{ Poor eating habits } \\
\hline & & $0^{a}$ & Single $^{b}$ & Multiple $^{c}$ \\
\hline & $\mathrm{N}$ & 16,325 & 11,093 & 4,304 \\
\hline \multirow[t]{2}{*}{ Age (years) } & Mean \pm SD & $56.3 \pm 8.2$ & $53.6 \pm 7.8$ & $51.5 \pm 7.6$ \\
\hline & $<65$ years, $\%$ & 86.5 & 93.8 & 96.6 \\
\hline \multirow[t]{3}{*}{ Exercise habits, n (\%) } & No & II,567 (70.9) & $8,645(77.9)$ & $3,555(82.6)$ \\
\hline & Yes & 4,743 (29.1) & $2,438(22.0)$ & $747(17.4)$ \\
\hline & Unidentified/unlisted & $15(0.1)$ & $10(0.1)$ & $2(0.0)$ \\
\hline \multirow[t]{3}{*}{ Smoking habit, n (\%) } & No & II,084 (67.9) & $6,750(60.8)$ & 2,297 (53.4) \\
\hline & Yes & $5,235(32.1)$ & $4,337(39.1)$ & $2,005(46.6)$ \\
\hline & Unidentified/unlisted & $6(0.0)$ & $6(0.1)$ & $2(0.0)$ \\
\hline \multirow[t]{4}{*}{ Alcohol consumption, n (\%) } & Daily & $4,215(25.8)$ & $3,507(31.6)$ & $\mathrm{I}, \mathrm{I} 54(26.8)$ \\
\hline & Sometimes & $5,254(32.2)$ & $3,327(30.0)$ & I,327 (30.8) \\
\hline & Rarely & 6,748 (4I.3) & $4,169(37.6)$ & $\mathrm{I}, 806(42.0)$ \\
\hline & Unidentified/unlisted & $108(0.7)$ & $90(0.8)$ & $17(0.4)$ \\
\hline \multirow[t]{3}{*}{ Adequate sleep, n (\%) } & No & $5,479(33.6)$ & $4,94 I(44.5)$ & $2,249(52.3)$ \\
\hline & Yes & $10,668(65.3)$ & $5,959(53.7)$ & $1,926(44.7)$ \\
\hline & Unidentified/unlisted & $178(I . I)$ & $193(1.7)$ & $129(3.0)$ \\
\hline HbAlc (\%) & Mean \pm SD & $7.17 \pm 1.26$ & $7.31 \pm 1.35$ & $7.55 \pm 1.53$ \\
\hline \multirow[t]{2}{*}{ Percentage of workers, $\%[95 \% \mathrm{Cl}]$} & $<7.0 \%$ & $53.1[52.3,53.8]$ & $48.2[47.3,49.2]$ & $42.1[40.6,43.5]$ \\
\hline & $\geq 7.0 \%$ & $46.9[46.2,47.7]$ & $51.8[50.8,52.7]$ & $57.9[56.5,59.4]$ \\
\hline$P$-value & Fisher's exact test & - & $<0.001$ & $<0.001$ \\
\hline BMI $\left(\mathrm{kg} / \mathrm{m}^{2}\right)$ & Mean $\pm S D$ & $25.7 I \pm 4.44$ & $26.70 \pm 4.59$ & $27.46 \pm 4.75$ \\
\hline \multirow[t]{2}{*}{ Percentage of workers, $\%[95 \% \mathrm{Cl}]$} & $<25 \mathrm{~kg} / \mathrm{m}^{2}$ & $48.9[48.2,49.7]$ & $38.6[37.7,39.5]$ & $32.2[30.8,33.6]$ \\
\hline & $\geq 25 \mathrm{~kg} / \mathrm{m}^{2}$ & $51.1[50.3,51.8]$ & $61.4[60.5,62.3]$ & $67.8[66.4,69.2]$ \\
\hline$P$-value & Fisher's exact test & - & $<0.001$ & $<0.001$ \\
\hline
\end{tabular}

Note: answered "No" to all questions; 'Answered "Yes" to one of the three questions; "Answered "Yes" to two or three questions.

Abbreviation: BMI, body mass index; HbAlc, glycated hemoglobin. 
A

$\mathrm{HbA} 1 \mathrm{c} \geq 7.0 \%$

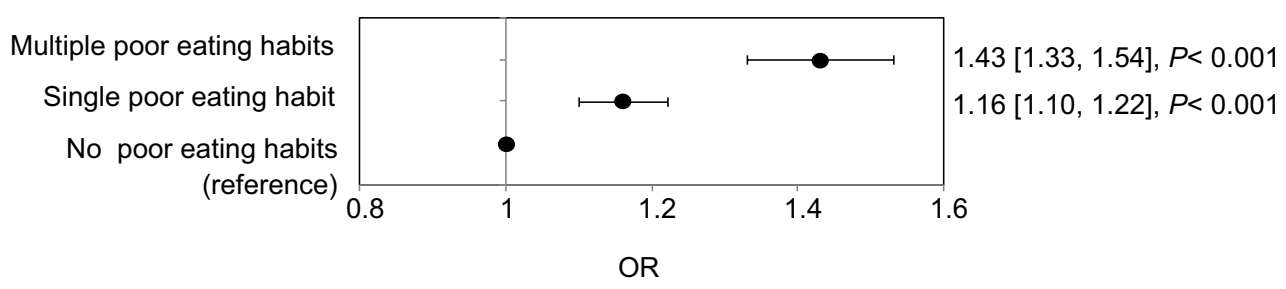

B $\quad B M I \geq 25 \mathrm{~kg} / \mathrm{m}^{2}$

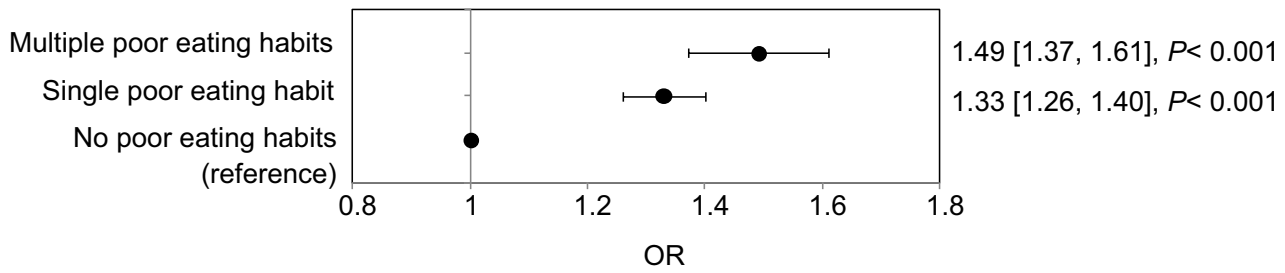

Figure 3 ORs ( $95 \% \mathrm{Cls}$ ) for (A) $\mathrm{HbAlc} \geq 7.0 \%$ and (B) BMI $\geq 25 \mathrm{~kg} / \mathrm{m}^{2}$ by poor eating habit.

Notes: The ORs, $95 \% \mathrm{Cls}$, and $P$-values were evaluated by multivariate logistic regression using sex, age, exercise habit, sleep, alcohol consumption, and diabetes treatment history as covariates. The reference subgroup was those workers who answered "No" to all three poor eating habit questions.

Abbreviations: BMI, body mass index; HbAlc, glycated hemoglobin.

because of decreased metabolic rate during sleep ${ }^{28}$ and fat oxidation. ${ }^{29}$ This pattern of eating also enhanced postprandial glucose excursion and elevated 24-hour average blood glucose levels. ${ }^{30}$ In addition, there was an inverse relationship between the frequency of breakfast consumption and the risk of obesity and T2DM. ${ }^{31-33}$ The mechanism of weight gain after skipping breakfast may include possible consumption of large meals as lunch and supper, and reduced thermogenesis, as the thermic effect of food in the morning is higher than it is during midday and night time. ${ }^{34}$ Skipping breakfast is associated with a significantly higher HbA1c and a higher hyperglycemic response to lunch and supper in people with T2DM. ${ }^{35,36}$ It has been shown that when breakfast was skipped, insulin, C-peptide, and intact glucagon-like peptide-1 levels were low, whereas glucagon and fatty acid levels were increased after lunch and supper. ${ }^{36}$ This resulted in higher postprandial blood glucose levels. Subgroups with single and multiple poor eating habits were associated with significantly higher HbA1c and BMI, and subgroups with multiple poor eating habits had higher ORs for hyperglycemia and obesity compared with the subgroup without any of these poor eating habits. These results suggest that each poor eating habit contributes to poor glycemic control and the development of obesity in workers with T2DM.

The subgroup of workers who described their eating speed as Fast tended to have higher BMIs than the subgroups whose eating speeds were Normal or Normal + Slow. A fast eating habit has been reported to be associated with high BMI in nondiabetic obese subjects ${ }^{37-39}$ and in people with T2DM. ${ }^{40}$ In contrast, HbA1c level was not associated with fast eating in the present study. A previous study showed no difference in post-meal changes in blood glucose and the secretion of insulin in people with T2DM between those given liquid nutrition over 20 minutes and over 5 minutes. ${ }^{41}$ Eating slowly while masticating may increase diet-induced thermogenesis after a meal, contributing to reduced body weight in obese subjects. ${ }^{42,43}$ Thus, the association between fast eating and high BMI but not HbA1c in the workers with T2DM in this study is consistent with that for people with T2DM in general population.

A limitation of this study was the lack of information about meal sizes, total energy consumption, constituents of meal or snack, and intake of nutraceutical/functional food, which plays a role in preventing metabolic syndrome, ${ }^{44}$ by the individual workers over the course of the day. In addition, the self-reported lifestyle assessment was qualitative and may have included reporting bias. Although these questionnaires are widely used for medical check-ups in Japan, cautious interpretation of results is necessary because the definition of each response criterion in questionnaires differs depending on studies. The insured members of health insurance associations were not representative of all types of work, and $92 \%$ of 
the workers in this study population were male. We could not define the workers diagnosed with T2DM who were treated by lifestyle intervention alone from medical claim, as a large number of workers with suspected T2DM was included in this database. Finally, this was a retrospective, cross-sectional, epidemiological study, which cannot prove causal relationships, with incomplete database records, in some cases.

Despite these limitations, this database study demonstrated associations between poor eating habits and poor glycemic control and obesity in Japanese workers with T2DM treated with antidiabetic agents. Because a divided supper ameliorates postprandial hyperglycemia in patients with T2DM, ${ }^{45}$ the results of this study suggest that improving eating habits would lead to improved glycemic and body weight control in workers with T2DM, as recommended in the American Heart Association's scientific statement. ${ }^{7}$ As the JMDC database includes medical check-up data for a large proportion of insured Japanese workers, a systematic analysis of this database may provide the opportunity to examine relationships between lifestyle and diseases.

\section{Conclusion}

In summary, the results of our database study using medical claim and medical check-up data showed that eating time, skipping breakfast, and eating speed were significantly associated with glycemic control and body weight in T2DM workers treated with antidiabetic agents. Improving eating habits may aid weight control and help in the glycemic management of T2DM patients.

\section{Acknowledgments}

The authors would like to express gratitude to the following co-workers: Hiroaki Matsuda and Takumi Tajima from Mitsubishi Tanabe Pharma Corporation, Chie Ito, Satoshi Kusakabe, and Rie Nishikino from the JMDC for valuable advice of the study and conducting the data analysis, and Akira Saito, PhD (International Medical Translation Service, Inc.), for providing medical writing support funded by Mitsubishi Tanabe Pharma Corporation.

\section{Author contributions}

All authors contributed toward the study design, data analysis, drafting and revising the paper and agree to be accountable for all aspects of the work.

\section{Disclosure}

All authors are employees of Mitsubishi Tanabe Pharma Corporation, Japan. The authors report no other conflicts of interest in this work.

\section{References}

1. Stratton IM, Adler AI, Neil HA, et al. Association of glycaemia with macrovascular and microvascular complications of type 2 diabetes (UKPDS 35): prospective observational study. BMJ. 2000;321(7258):405-412.

2. Lavigne JE, Phelps CE, Mushlin A, Lednar WM. Reductions in individual work productivity associated with type 2 diabetes mellitus. Pharmacoeconomics. 2003;21(15):1123-1134.

3. American Diabetes Association. Economic Costs of Diabetes in the U.S. in 2017. Diabetes Care. 2018;41(5):917-928.

4. Uehara A, Kurotani K, Kochi T, et al. Prevalence of diabetes and prediabetes among workers: Japan Epidemiology Collaboration on Occupational Health Study. Diabetes Res Clin Pract. 2014;106(1):118-127.

5. Gotay CC, Shimizu H, Muraoka M, Ishihara Y, Tsuboi K, Ogawa H. Health attitudes and behaviors: comparison of Japanese and Americans of Japanese and European Ancestry. Health Place. 2004;10(2):153-161.

6. Sato M, Yamazaki Y. Work-related factors associated with self-care and psychological health among people with type 2 diabetes in Japan. Nurs Health Sci. 2012;14(4):520-527.

7. St-Onge MP, Ard J, Baskin ML, et al. Meal Timing and Frequency: Implications for Cardiovascular Disease Prevention: A Scientific Statement From the American Heart Association. Circulation. 2017;135(9):e96-e121.

8. Morse SA, Ciechanowski PS, Katon WJ, Hirsch IB. Isn't this just bedtime snacking? The potential adverse effects of night-eating symptoms on treatment adherence and outcomes in patients with diabetes. Diabetes Care. 2006;29(8):1800-1804.

9. Watanabe Y, Saito I, Henmi I, et al. Skipping Breakfast is Correlated with Obesity. J Rural Med. 2014;9(2):51-58.

10. Nakajima K, Suwa K. Association of hyperglycemia in a general Japanese population with late-night-dinner eating alone, but not breakfast skipping alone. J Diabetes Metab Disord. 2015;14:16.

11. Sakurai M, Yoshita K, Nakamura K, et al. Skipping breakfast and 5-year changes in body mass index and waist circumference in Japanese men and women. Obes Sci Pract. 2017;3(2):162-170.

12. Bi H, Gan Y, Yang C, Chen Y, Tong X, Lu Z. Breakfast skipping and the risk of type 2 diabetes: a meta-analysis of observational studies. Public Health Nutr. 2015;18(16):3013-3019.

13. Uemura M, Yatsuya H, Hilawe EH, et al. Breakfast Skipping is Positively Associated With Incidence of Type 2 Diabetes Mellitus: Evidence From the Aichi Workers' Cohort Study. J Epidemiol. 2015;25(5):351-358.

14. Allison KC, Goel N. Timing of eating in adults across the weight spectrum: Metabolic factors and potential circadian mechanisms. Physiol Behav. 2018;192:158-166.

15. Kuwahara K, Uehara A, Yamamoto M, et al. Current status of health among workers in Japan: Results from the Japan Epidemiology Collaboration on Occupational Health Study. Ind Health. 2016;54(6):505-514.

16. Haneda M, Noda M, Origasa H, et al. Japanese Clinical Practice Guideline for Diabetes 2016. J Diabetes Investig. 2018;9(3):657-697.

17. Saito Y, Shirai K, Nakamura T, et al. Diagnostic criteria for obesity 2011. J Jpn Soc Study Obesity. 2011;17(s):1-78.

18. Nishiyama M, Muto T, Minakawa T, Shibata T. The combined unhealthy behaviors of breakfast skipping and smoking are associated with the prevalence of diabetes mellitus. Tohoku J Exp Med. 2009;218(4):259-264.

19. Sakata K, Matumura Y, Yoshimura N, et al. Relationship between skipping breakfast and cardiovascular disease risk factors in the national nutrition survey data. Nihon Koshu Eisei Zasshi. 2001;48(10):837-841 [in Japanese].

20. Hattori T, Konno S, Munakata M. Gender Differences in Lifestyle Factors Associated with Metabolic Syndrome and Preliminary Metabolic Syndrome in the General Population: The Watari Study. Intern Med. 2017;56(17):2253-2259.

21. Stark Casagrande S, Fradkin JE, Saydah SH, Rust KF, Cowie CC. The prevalence of meeting A1C, blood pressure, and LDL goals among people with diabetes, 1988-2010. Diabetes Care. 2013;36(8):2271-2279.

22. Quah JH, Liu YP, Luo N, How CH, Tay EG. Younger adult type 2 diabetic patients have poorer glycaemic control: a cross-sectional study in a primary care setting in Singapore. BMC Endocr Disord. 2013;13:18. 
23. Hu H, Hori A, Nishiura C, et al. Hba1c, Blood Pressure, and Lipid Control in People with Diabetes: Japan Epidemiology Collaboration on Occupational Health Study. PLoS One. 2016;11(7):e0159071.

24. Ministry of Health, Labour and Welfare. Overview of the National Health and Nutrition survey results. 2012. Available from: http://www. nibiohn.go.jp/eiken/english/research/pdf/nhns2012.pdf. Accessed July 23, 2018.

25. Sugimoto H, Nakaishi S, Isogaya $H$, et al. A multiclinical study on the cessation of treatment for type 2 diabetic patients. J Japan Diab Soc. 2013;56(10):744-752.

26. Kirwan JP, Sacks J, Nieuwoudt S. The essential role of exercise in the management of type 2 diabetes. Cleve Clin J Med. 2017;84(7 Suppl 1):S15-S21.

27. Sakurai M, Nakamura K, Miura K, et al. Self-reported speed of eating and 7-year risk of type 2 diabetes mellitus in middle-aged Japanese men. Metabolism. 2012;61(11):1566-1571.

28. Katayose Y, Tasaki M, Ogata H, Nakata Y, Tokuyama K, Satoh M. Metabolic rate and fuel utilization during sleep assessed by whole-body indirect calorimetry. Metabolism. 2009;58(7):920-926.

29. Hibi M, Masumoto A, Naito Y, et al. Nighttime snacking reduces whole body fat oxidation and increases LDL cholesterol in healthy young women. Am J Physiol Regul Integr Comp Physiol. 2013;304(2):R94-R101.

30. Sato M, Nakamura K, Ogata H, et al. Acute effect of late evening meal on diurnal variation of blood glucose and energy metabolism. Obes Res Clin Pract. 2011;5(3):e169-e266.

31. Pereira MA, Erickson E, Mckee P, et al. Breakfast frequency and quality may affect glycemia and appetite in adults and children. J Nutr. 2011;141(1):163-168.

32. Timlin MT, Pereira MA. Breakfast frequency and quality in the etiology of adult obesity and chronic diseases. Nutr Rev. 2007;65(6 Pt 1):268-281.

33. Horikawa C, Kodama S, Yachi Y, et al. Skipping breakfast and prevalence of overweight and obesity in Asian and Pacific regions: a meta-analysis. Prev Med. 2011;53(4-5):260-267.

34. Romon M, Edme JL, Boulenguez C, Lescroart JL, Frimat P. Circadian variation of diet-induced thermogenesis. Am J Clin Nutr. 1993;57(4):476-480.

35. Reutrakul S, Hood MM, Crowley SJ, Morgan MK, Teodori M, Knutson KL. The relationship between breakfast skipping, chronotype, and glycemic control in type 2 diabetes. Chronobiol Int. 2014;31(1):64-71.
36. Jakubowicz D, Wainstein J, Ahren B, Landau Z, Bar-Dayan Y, Froy O. Fasting until noon triggers increased postprandial hyperglycemia and impaired insulin response after lunch and dinner in individuals with type 2 diabetes: a randomized clinical trial. Diabetes Care. 2015;38(10):1820-1826.

37. Otsuka R, Tamakoshi K, Yatsuya H, et al. Eating fast leads to obesity: findings based on self-administered questionnaires among middle-aged Japanese men and women. J Epidemiol. 2006;16(3):117-124.

38. Ohkuma T, Fujii H, Iwase M, et al. Impact of eating rate on obesity and cardiovascular risk factors according to glucose tolerance status: the Fukuoka Diabetes Registry and the Hisayama Study. Diabetologia. 2013;56(1):70-77.

39. Ohkuma T, Hirakawa Y, Nakamura U, Kiyohara Y, Kitazono T, Ninomiya T. Association between eating rate and obesity: a systematic review and meta-analysis. Int J Obes (Lond). 2015;39(11):1589-1596.

40. Saito A, Kawai K, Yanagisawa M, et al. Self-reported rate of eating is significantly associated with body mass index in Japanese patients with type 2 diabetes. Japan Diabetes Clinical Data Management Study Group (JDDM26. Appetite. 2012;59(2):252-255.

41. Kamiko K, Aoki K, Kamiyama H, Taguri M, Terauchi Y. Comparison of Plasma Glucose and Gut Hormone Levels Between Drinking Enteral Formula Over a Period of 5 and 20 Minutes in Japanese Patients With Type 2 Diabetes: A Pilot Study. J Clin Med Res. 2016;8(10):749-752.

42. Hamada Y, Kashima H, Hayashi N. The number of chews and meal duration affect diet-induced thermogenesis and splanchnic circulation. Obesity (Silver Spring). 2014;22(5):E62-E69.

43. Hamada Y, Miyaji A, Hayashi N. Effect of postprandial gum chewing on diet-induced thermogenesis. Obesity (Silver Spring). 2016;24(4):878-885.

44. Scicchitano P, Cameli M, Maiello M, et al. Nutraceuticals and dyslipidaemia: Beyond the common therapeutics. J Funct Foods. 2014;6:11-32.

45. Imai S, Kajiyama S, Hashimoto Y, et al. Divided consumption of late-night-dinner improves glycemic excursions in patients with type 2 diabetes: A randomized cross-over clinical trial. Diabetes Res Clin Pract. 2017;129:206-212. 


\section{Supplementary materials}

A Prescription of antidiabetic agents
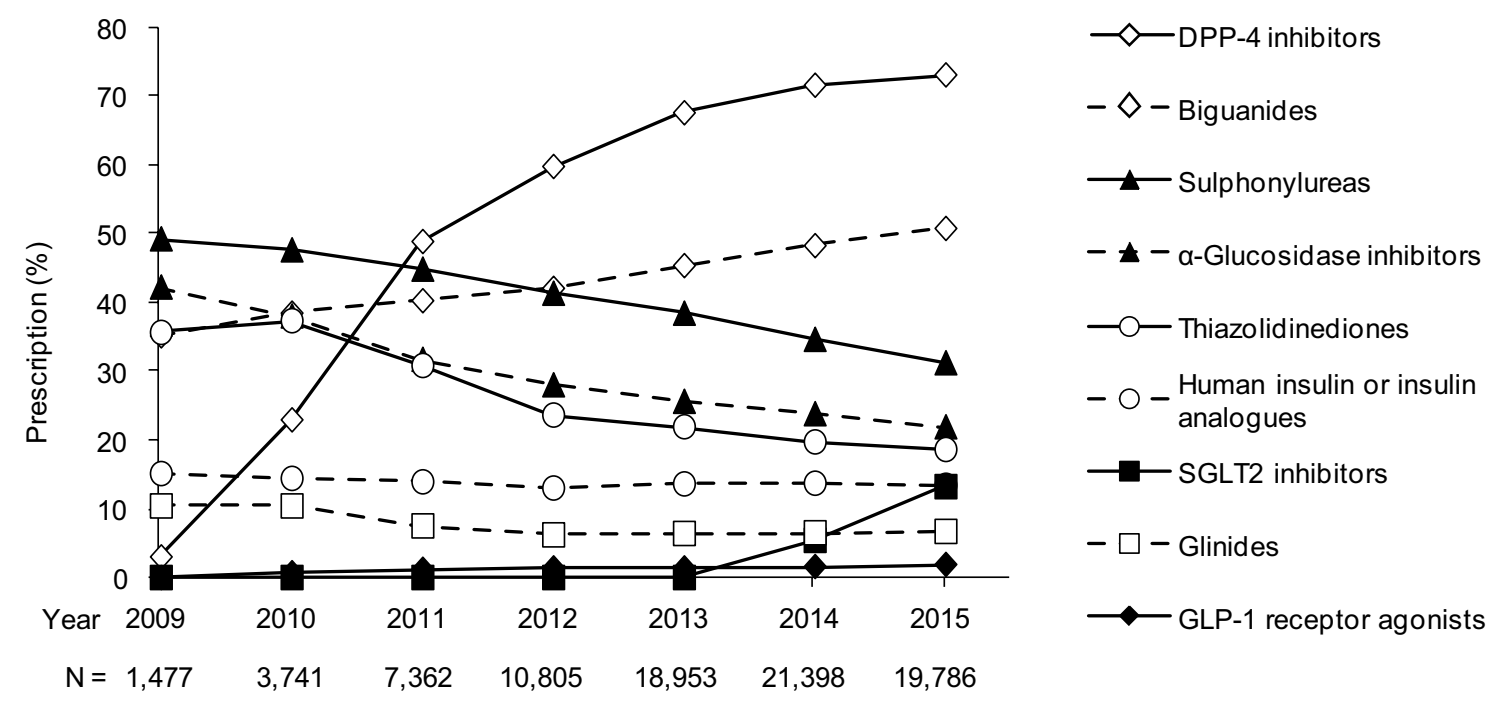

B $\quad \mathrm{HbA} 1 \mathrm{c}$

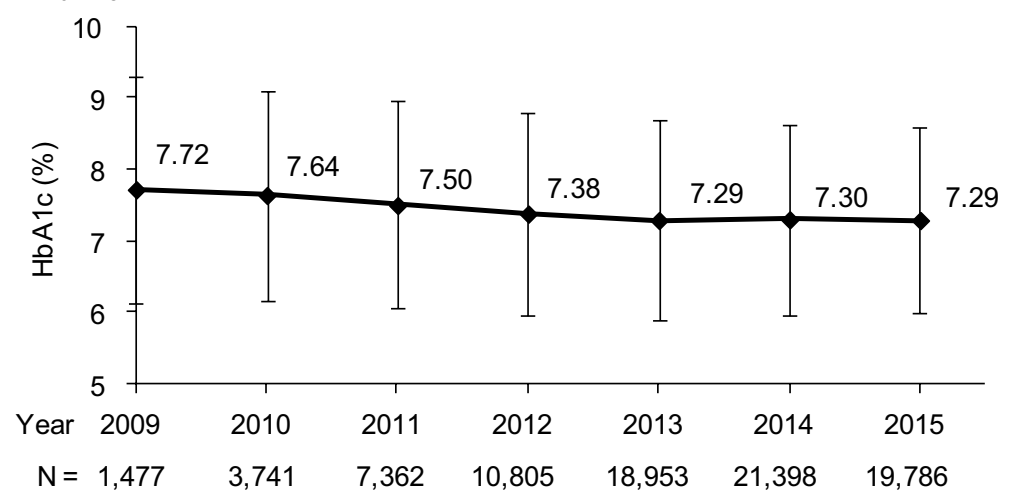

C BMI

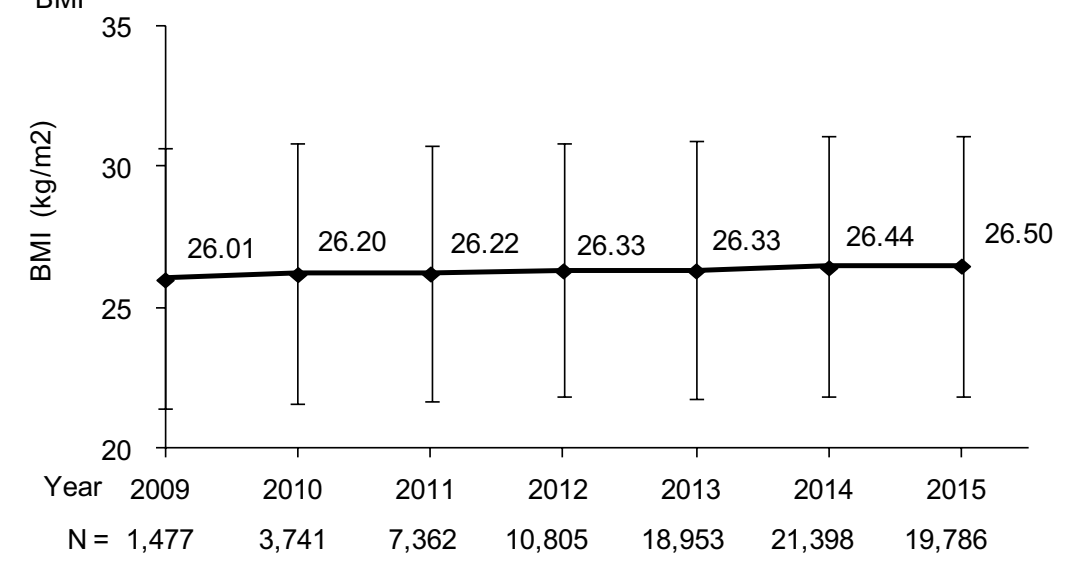

Figure SI Time course changes in (A) Prescription of anti-diabetic agents, (B) HbAlc, and (C) BMI in workers with T2DM.

Note: Data in graphs (B) and (C) are means \pm standard deviation.

Abbreviations: BMI, body mass index; DPP-4, dipeptidyl peptidase-4; GLP-I, glucagon-like peptide-I; HbA Ic, glycated hemoglobin; SGLT2. sodium-glucose co-transporter-2. 
General population: N=3,621,610

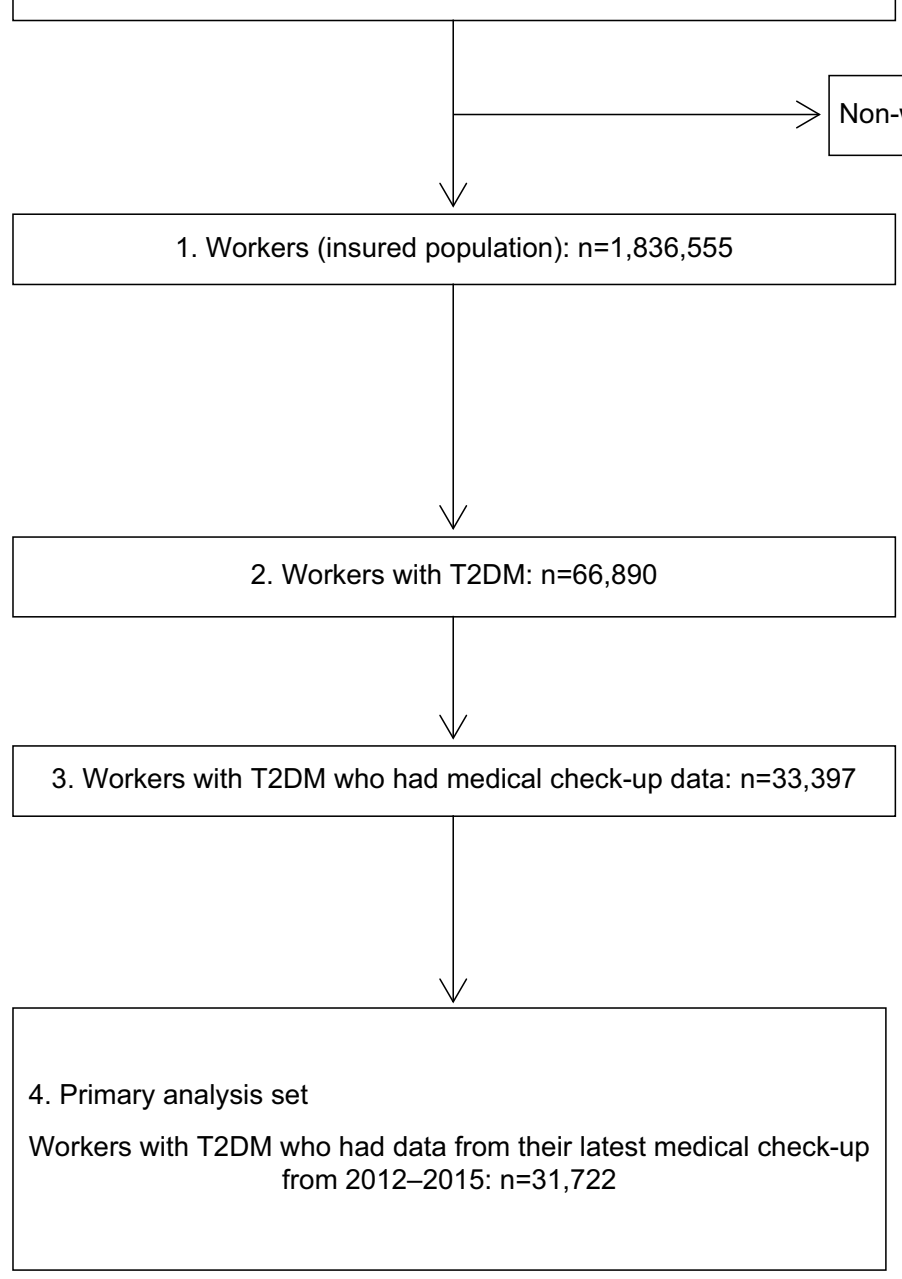

Figure S2 Sampling design.

Note: (1) Workers were defined as insured members of health insurance associations between 2009 and 2015; (2) T2DM was identified by a disease classification code of EI I or EI4 in the International Classification of Diseases and antihyperglycemic agents include those with the following Anatomical Therapeutic Chemical classification system sub-code (AIOC, AIOH, AIOJ, AIOK, AIOL, AIOM, AION, AIOP, AIOS); (3) The data set of T2DM workers include medical check-up data including both HbAIc and BMI values; (4) Primary analysis set included workers with T2DM with a latest medical check-up record between 2012 and 2015.

Abbreviation: T2DM, type 2 diabetes mellitus.

\section{Publish your work in this journal}

Diabetes, Metabolic Syndrome and Obesity: Targets and Therapy is an international, peer-reviewed open-access journal committed to the rapid publication of the latest laboratory and clinical findings in the fields of diabetes, metabolic syndrome and obesity research. Original research, review, case reports, hypothesis formation, expert opinion and commentaries are all considered for publication. The manuscript management system is completely online and includes a very quick and fair peer-review system, which is all easy to use. Visit http://www.dovepress.com/testimonials.php to read real quotes from published authors.

Submit your manuscript here: https://www.dovepress.com/diabetes-metabolic-syndrome-and-obesity-targets-and-therapy-journal 